\title{
EL CASTILLO Y EL VALLE DE POP DURANTE LA EDAD MEDIA: CONTRIBUCION AL ESTUDIO DE LOS SEÑORIOS VALENCIANOS
}

\author{
Pierre Guichard \\ Universidad Lyon II
}

Entre los topónimos históricos de la provincia de Alicante a la vez más conocidos y más misteriosos, figura sin duda el nombre de Pop. Los cronistas e historiadores valencianos, $y$ en primer lugar Escolano, nos ofrecen extensos relatos del largo asedio de los moriscos refugiados en Pop en el momento de la expulsión. En la Gran Enciclopedia de la región valenciana figuran varias reproducciones de cuadros pertenecientes a una serie de lienzos del siglo XVII cuyo tema es la expulsión de los moriscos. Uno de ellos representa a dichos moriscos sitiados en el castillo de Pop simbolizado por una torre de dos pisos asentada en la cima de un pico (1). En su libro sobre Alcalali publicado en 1970, Joaquín Mestre Palacio dedica varias páginas y algunos documentos gráficos al castillo de Pop y al monte llamado "del Cavall Verd», cercano a Murla, en el que se habría erguido (2). Con ocasión del Primer Congreso de Historia del País Valenciano de 1971, el mismo autor volvió sobre el tema presentando una comunicación en la que proponía iden-

(1) Gran Enciclopedia de la región valenciana, t. 9 Nalencia, 1973), pág. 107 (propiedad particular).

(2) J. MESTRE PALACIO, Alcalall, Alicante, 1970, págs, 127-134. En el trabajo toponimico de F. DE MELCHOR I RAMON-BAVIERA, V. SEGUI I ALEMANY, T. PARICIO I GARCIA, Aproximació a la toponimia del País Valencià, Valencia, 1978, este monte aparece como "tossal del Cavall Verd" o "tossal de Pop" (pág. 184). 
tificar el "Ondia" mencionado en la Gesta Roderici Campidocti como lugar de la región de Denia ocupado y fortificado por el Cid a inicios del año 1090, con la "Ombria" del mencionado castillo de Pop (3).

En ambos trabajos, Joaquín Mestre se atreve a proponer una reproducción ideal, o mejor dicho una reconstitución, del famoso castillo que hubiera presentado dos cuerpos distintos unidos entre sí por una muralla doble que flanqueaba la cresta que mediaba entre los dos. Supongo que para tal reconstitución se habrá utilizado, además de una foto del Peñón de Laguart, la descripción del lugar que hace Escolano: "En lo más eminente (de la sierra situada entre los valles de Alahuar y Murla-Benichemblal hubo antiguamente un castillo que se llamaba del Pop, en cuyo sitio aún quedan parte de las ruinas. Es fortisimo de suyo, y no se puede subir a él sino por una áspera entrada, y uno a uno. Corriendo deste castillo, hacia la parte de Murla y de Levante, tiene otra punta de peña que entre las dos hace una quebrada con algunos pasos de llano; y la punta es muy fuerte y áspera y por caer sobre Murla se descubre della la plaza, calles y puertas. Estas dos puntas con el llano de en medio forman una silla de caballo con sus dos arzones: de donde vino que los̀ moros llamasen esta sierra el Caballo Verde, por estar toda cubierta de yerbas; y estas dos las tenian ocupadas los moros desde el primer día de su levantamienton (4).

Pero al historiador o arqueólogo que, movido por el deseo de estudiar los restos de tan histórico castillo, sube hasta la cumbre del citado monte - llamado más corrientemente "Peñón de Laguart»- le espera la sorpresa de no encontrar allí arriba ningún vestigio de construcción. No se ven los lienzos de recinto, restos de cisternas, que suelen aparecer en los antiguos castillos musulmanes de la zona (5). La misma topografía no responde exactamente a la que se acostumbra observar en la mayoría de los sitios donde existió en la Edad Media valenciana un castillo musulmán (hisn) al que sucedió luego uno cristiano (castrum): El lugar es muy alto, y la parte que pudo servir de refugio natural, en cambio, es relativamente pequeña, y quizás no tan bien defendida natu-

(3) J. MESTRE PALACIO, "Rectificación de la ruta que siguió el Cid desde Elche a Valencia", Primer Congreso de Historia del Pais Valenciano Nalencia, 14-18 de abril de 1971), vol. II, Univ. de Valencia, 1980, págs. 419-425.

(4) G. ESCOLANO, Décadas de la Historia..., ed. J. B. PERALES, Valencia, 1878, 2." parte, pág. 803. Las Décadas fueron publicadas en 1611, o sea, tres años sólamente después de la expulsión, y la descripción de los lugares es tan pormenorizada que cabe pensar que el autor o sus informadores los conocian muy bien.

(5) Se puede comparar la pobreza de los vestigios de Pop con la importancia de los recintos de los castillos de Perpunchent (Lorcha) o Pego, ambos antiguos husun musulmanes. 
ralmente como acostumbra ser en otros "castillos" más o menos cercanos en los que, sin carecer en absoluto como en este caso, las construcciones son muy pobres (6). El hecho de que no existen en la actualidad los vestigios de construcción que se podrían esperar ha llevado a algunos de los que se han interesado por el castillo de Pop a pensar que no había existido, o que convenía buscarlo en otro sitio. Las leyendas que se han formado en torno al pico y al desaparecido castillo (7), tanto como el hecho de que el mismo topónimo de Pop parece haber caído en desuso, pueden haber contribuido a incrementar tales dudas. Sin embargo, quizás no cabe sacar conclusiones apresuradas de la inexistencia de estructuras "castrales" en el Peñón de Laguart, sino que conviene reparar en otro hecho, positivo, apuntado por Joaquín Mestre, que es la gran abundancia "de los fragmentos de cerámica ibérica, romana y árabe diseminados desde la cima de ambos picos hasta las orillas inferiores de sus faldas, a donde llegan arrastrados por las aguas, con tanta profusión que apenas hay metro cuadrado en el que no se puedan identificar cántaros, tinajas, ánforas, orzas, cazuelas, jarras, tazas, escudillas, tenas o ladrillos, etc. (8).

Mi propósito no es hacer un estudio arqueológico del Peñón, al que he subido solamente dos veces, $y$ en el que no he pasado sino unas pocas horas. Convendría trabajar con una documentación cartográfica y fotográfica que no tengo a mano de momento, y dedicarse a una prospección sistemática del lugar, con el correspondiente estudio de la cerámica, para determinar las posibles fases de ocupación humana del mismo. No se pueden descartar varias hipótesis, entre las cuales hay que incluir la de una ocupación solamente temporal, en tiempos de peligro, sirviendo el pico de refugio para los hombres que tenían sus moradas en el llano. Su última utilización en cuanto tal hubiera ocurrido cuando la expulsión de los moriscos, y podríamos pensar que parte de la cerámica que se encuentra en las faldas del Peñón corresponde a esta época. Sin embargo, me parece difícil admitir que la gran cantidad de tiestos que se puede observar en la parte alta del monte se relacione con un acontecimiento tan breve (9). Por mi parte, he encon-

(6) El castillo de Segarria, por ejemplo, en término de Benimeli, se reduce a una gran plataforma rocosa naturalmente defendida por unos acantilados impresionantes. Los únicos restos de construcción son dos cisternas y unos muros de poca extensión para defender los dos accesos posibles del refugio.

(7) Véase J. MESTRE, A/calali, pág. 133.

(8) J. MESTRE, Alcalali, pág. 133.

(9) Los moriscos del valle de Alaguar habian ocupado las cimas del Peñón inmediatamente después de la proclamación del bando de expulsión (22 de septiembre de 1609), pero 
trado cerca de las dos cumbres, en sus faldas meridionales y dentro de la vaguada formada entre ellas, abundantes muestras de cerámicas bastas que me parecen remontar mucho más allá de la época moderna, y varios tiestos de cuencos que deben corresponder a los últimos siglos del período musulmán (10).

Otra hipótesis, apuntada también por Joaquín Mestre y que podría explicar la falta de restos de construcciones, es la de una destrucción intencionada del "castillo" en determinada época (11). A veces, se habla de tal destrucción, de carácter simbólico, posteriormente a la expulsión, pero no he encontrado huella documental del hecho. De todas formas, conocemos otros castillos "destruidos", como el cercano castillo de Alaguar o de las Azabaras, de los que quedan restos mucho más evidentes (12). En cambio, de haber existido en alguna época un establecimiento humano en estas cimas rocosas, pudo ser de una edificación muy pobre, y no me parece imposible que sus casas de piedra seca hayan sido destruidas por completo tanto por la fuerza de la erosión como por los cultivos y los bancales que, durante los siglos XVIII y $\mathrm{XIX}$, parecen haber alcanzado casi las mismas cumbres del Peñón. Un argumento en contra de la existencia del "castillo" de Pop en el Peñón es que, al revés de lo que ocurre en los demás sitios castrales de la zona, no se observa en este ninguna cisterna. Creo que conviene, de momento, dejar esta cuestión pendiente, pero no me parece que tenga bastante fuerza para invalidar la creencia tradicional de que fue efectivamente en este monte donde existió, en la Edad Media, el castrum de Pop al que alude una larga y continua serie de documentos que, desde la conquista cristiana hasta por lo menos los primeros años del siglo XV mencionan dicho castillo. No he estudiado la documentación mo-

no fueron atacados antes de la llegada a Murla de las tropas mandadas para combatirlos, a mediados de noviembre. Es entonces cuando las familias de moriscos de las montañas de Denia, o parte de ellas, que se habían concentrado en el valle de Alaguar, se refugiaron en el pico del Cavall Verde. La rendición de los moriscos de Pop tuvo lugar el día 29 del mismo mes de noviembre, así que la estancia de un gran número de gente en dicho "castillo" no duró más que unos quince días.

(10) Abundan los tiestos de cerámica basta, que han pertenecido a grandes lebrillos o cántaros. Presentan un tipo de pasta con mucho desgrasante, bastante común en los yacimientos musulmanes de esta zona. Se encuentran también fragmentos de cuencos o ataifores con vidriado verde turquesa, que parecen situarse cronológicamente alrededor del siglo XII.

(11) Pág. 132.

(12) El rey Pedro III el Grande, en 1283, ordenó que se destruyese el castillo de Alaguar, según documento del Archivo de la Corona de Aragón (A.C.A.), Reg. Canc. 46, fol. 105 v., transcrito en el libro de J. MESTRE, pág. 663. De dicho castillo, conocido como ude las Azabaras", quedan restos de cisterna y algunos lienzos de muros. 
derna correspondiente a los dos siglos que median entre aquella época y la de la expulsión, pero me extrañaría que, durante este periodo de tiempo, el recuerdo del castillo de Pop se haya borrado hasta el punto de que los contemporáneos del asedio de los moriscos sitiados en la cumbre de Cavall Verd confundiesen dicho punto con el histórico castrum que convendría, en este caso, buscar en otro sitio. No creo que se conozca en el antiguo valle de Pop otro yacimiento medieval del mismo tipo. Además, es muy lógico que, como ocurrió en el caso del castillo de Alaguar —o de las Azabaras - los moriscos hayan buscado el amparo de lo que habia sido, en tiempos remotos, un refugio tradicional para los habitantes del valle.

He procurado varias veces, en otros trabajos, analizar el papel y las funciones del "castillo" o hisn en la organización socio-política del oriente peninsular antes de la conquista cristiana (13). Los castillos o husun se nos aparecen como poblados o refugios, o ambas cosas a la vez, ligados a una comunidad campesina o aljama más que a una autoridad de tipo señorial. Cada uno de ellos sirve de centro a una de estas aljamas, cuyos miembros, que viven bien en las alquerias o pobladitos del llano, bien en el poblado de altura que corresponde al mismo hisn, cultivan y poseen conjuntamente un término bien delimitado. Este último, que forma generalmente una unidad natural o "valle", lleva casi siempre el mismo nombre que el castillo. En realidad, es probablemente el nombre del distrito el que antecede generalmente al del castillo, como en el caso de Guadalest en el que el valle (wadi) ha servido para denominar el castillo de Wadi Last (14). En el momento de la conquísta de estas tierras por los critianos (1244-1245), aparecen en el texto árabe del famoso pacto firmado por al-Azraq con el rey Jaime I los nombres de ocho de los husun de la zona, entre los cuales figura el de $B u ̂ b$ o Pop (15). El documento no indica cuál era entonces el carácter de este "castillo", pero en el primer documento cristiano en el que vuelve a salir el nombre del castillo de Pop, cuya alcaidía el rey concedió en 1258 al almirante Carroz, señor de Rebollet, se menciona como

(13) Véase mi contribución a la historia de Valencia publicado bajo el título: Nuestra Historia, Valencia, 1980, tomo Il, págs. 264-277.

(14) J. BOSCH VILA, "notas de toponimia para la historia de Guadalest y su valle», Miscellanea de estudios árabes y hebraicos, XII, 1963, págs. 47-74.

(15) Texto publicado, traducido y reproducido en facsímil en: Francisco de P. MOMBLANCH, Al-Azraq, capitán de moros, Valencia, 1977. 
"castrum et villa", lo cual haría pensar que el hisn correspondía todavía, o había correspondido poco antes, a un establecimiento humano permanente (16). Esta cualificación de villa se encuentra todavía en otras dos concesiones del castillo a Ramón de Villanova en 1296 y 1305 (17), pero puede ser significativo de la desaparición de tal villa el hecho de que, en un tercer documento al mismo personaje, del año 1313 , la expresión "castrum et villa" sea sustituida por la de "castrum et vallem" (18).

Los límites del mencionado valle de Pop, o término de Pop, quedan indicados en la primera concesión a Vidal de Vilanova, y vuelven a repetirse en una donación posterior al infante Pedro, hijo de Jaime II, en 1322: lindaba con los términos de Alaguar, Castell de Castells, Jalón y Tárbena (19), con lo que queda perfectamente dibujado el término por sus lados Norte, Oeste y Sur, en los que correspondía con los actuales de Benichembla y Parcent, o sea con la unidad geográfica formada por el valle del río Jalón. Hacia el Este, una línea de pequeñas alturas (tosal de Isidro) separan el término de Parcent del de Alcalalí, que pertenecía a Jalón. Hacia el Nordeste, el término de Pop lindaba con el de Alaguar, que incluía el municipio actual de Orba (20), con lo cual se encontraba delimitado naturalmente por las notables alturas que separan los términos de Orba y Murla, y en primer lugar el Puig d'Orba en el que será edificado más tarde el llamado castillo de Orba. Este término de Pop, por lo tanto, correspondía a los $36,29 \mathrm{~km}^{2}$ que suman los municipios de Benichembla, Murla y Parcent. Los nombres de varias de sus alquerías figuran en el segundo volumen del Repartiment de Valencia, en el que se registran donaciones de tierras a cristianos en las alquerías de Pop llamadas Parsen, Ceylent, Merniça, Benigela, Rahalabelbahar, Benalbacar, Alcanicia y Benilacruci (21), de los cuales dos solamente (Parcent y Benichembla) han subsistido hasta nuestros días, conservándose ade-

(16) A.C.A., Reg. 9, fol. $39 \mathrm{r}-\mathrm{v}$; documento del 19 de septiembre de 1258 , publicado por J. MESTRE PALACIO, Alcalali, pág. 656.

(17) A.C.A., Reg. 194, fol. $265 \mathrm{r}-\mathrm{v}$, y 203 , fol. $92 \mathrm{r}$.

(18) A.C.A., Reg. 210 , fol. $59 \mathrm{r}-\mathrm{v}$, et A.R.V. (Archivo del Reino de Valencia, Real Patrimonio), libro 614, fol. 107.

(19) A.C.A., Reg. 475 , fol. 90 v.

(20) A finales del siglo XIV, todavía se menciona la pertenencia del actual término de Orba al valle de Alaguar (A.C.A., Reg. 2.191, fol. 99 r; doc. del 1 de octubre de 1398).

(21) Repartiment de Valencia, vol. 2, ed. M.-D. CABANES y R. FERRER, Zaragoza, 1979, números 1.011 y 1.041 . En un documento de 1309 sale el nombre de otra alquería llamada Benivaquer (A.C.A., Reg. 216, fol. $128 \mathrm{v}-129$ r). Murla, que no aparece en el Repartiment, pertenecia también al valle de Pop como se indica en el documento de 1273 al que se refiere la nota 23. 
más en la toponimia Alcanicia (La Canessia) y Merniça (Bernisa o Vernisa).

No queda documentación que podría aportar datos sobre el modo en el que se repartió efectivamente la propiedad de las tierras del valle. Ignoramos, por otra parte, si los primeros pobladores pudieron establecerse en él y mantenerse tras las sublevaciones musulmanas que se produjeron en los años siguientes. Es al terminar la segunda sublevación de al-Azraq, en 1258, cuando Jaime I hizo a Carroz la concesión vitalicia del castillo de Pop a la que se ha aludido más arriba, dándole facultad para establecer sus casas y tierras, pero a musulmanes solamente (22). La documentación posterior indica que Murla fue la única población del valle de Pop en la que se asentaron unos cristianos, pero no sabemos a partir de qué fecha. El lugar adquiere pronto un estatuto especial respecto a las demás alquerías, cuyos nombres, después de haber sido consignados por primera y única vez en el texto del Repartiment, no vuelven a salir en los documentos, confundidos en el mismo anonimato del "valle de Pop» o del «castrum de Pop». Esta instalación de cristianos, sin embargo, no parece ser anterior a la última sublevación musulmana de los años 1276-1277, pues una donación de la alqueria de Murla al burgués de Montpeller Berenguer de Molins, fechada en 4 de febrero de 1273, no alude sino a musulmanes (23). En el mismo documento, sin embargo, se menciona un mercado, lo que indica que la alquería era ya la población más importante del valle (24). La misma alquería de Murla fue sin duda vendida luego por su primer señor, pues en el año 1289 la encontramos en manos de un burgués de Valencia, Berenguer Mercer, al que el rey concede en feudo el puig de Orba cercano a la alquería para que edifique en él una torre, casa fuerte o fortaleza. Según el documento, la concesión incluye todo el terreno que se extiende entre la cumbre del monte y la alquería de Murla por una parte, y la Portella de Alaguar y un lugar llamado Pillar (?) por otra, o sea, toda la extremidad Nordeste del término de Pop que lindaba con el de Alaguar. El rey precisa además que en el caso de que alienase el castillo de Pop o el de Alaguar, los señores de dichos castillos no ejercerían ningún derecho ni jurisdicción sobre el nuevo feudo. Mientras quedan en poder del rey, éste sigue gozando en la alqueria de Murla y el puig de Orba de "los derechos que le pertenecen en las demás alquerías alodiales del reino de Valencia" (25).

(22) Doc. indicado en la nota 16.

(23) A.C.A., Reg. 21, fol. 90 v.

(24) El mercado pertenece entonces al almirante Carroz, alcaide del castillo de Pop.

(25) A.C.A., Reg. 78, fol. 32 r. 
Este documento es muy importante en la historia del valle de Pop, pues además de darnos la fecha de construcción del castillo cristiano llamado de Murla o del Puig d'Orba, permite aclarar el hecho de que los documentos nos hablan luego de tres realidades distintas que son:

1) El antiguo castillo de Pop, con su valle y sus alquerías pobladas de musulmanes.

2) La alquería de Murla en la que aparecen pronto pobladores cristianos.

3) El nuevo castillo de Murla (o Puig d'Orba), más conocido ahora como castillo de Orba, que sus señores tienen en feudo del rey.

Vamos a estudiar brevemente el destino de cada una de esas realidades.

Como la mayoría de los castillos valencianos, el hisn musulmán de Pop constituyó inicialmente una alcaidía, sistema de tenencia que Ramón d'Abadal define como una "procuracio militar a precari", que no tiene nada que ver con un feudo (26). Ya vimos que el primer concesionario fue el famoso almirante Carroz, señor de Rebollet, que durante los años inmediatos a la conquista cristiana de la zona de Denia ejerció un verdadero "virreinato" en la región como alcaide de Denia y de los castillos de Segarria, Alaguar, Pop, Jalón, Calpe, Olocaiba y Polop, con poderes para repartir tierras en los mismos términos (27). En 1279, encontramos a otro alcaide, Arnaldo de Roas, encargado del castillo, con un sueldo anual de mil sueldos (28). En 1288, se le sustituye otro alcaide, Ramón de Urgio, pero éste cobra, por sus gastos y por la retinencia del castillo, todas las rentas del castillo (29). De dos documentos de los mismos años, se puede deducir que se habian realizado obras en el castillo (30). A los pocos años, en 1296, se producía la concesión

(26) R. D'ABADAL VINYALS, «Les 'Partidas' a Catalunya durant l'Edat Mitja", Estudis Universitaris Catalans, VI, 1912, pág. 49.

(27) J. E. MARTINEZ FERRANDO, Catálogo de los documentos del antiguo reino de Valencia, I, do. n..$^{\circ} 40$ del 24 de septiembre de 1257; J. MESTRE PALACIO, Alcalali, págs. 656-657, doc. del 19 de septiembre de 1258; El rey habia encomendado el repartimiento de Denia a Carroz en 1246 (HUICl-CABANES, Documentos de Jaime I, $11, n .{ }^{\circ} 420$, págs. 210-211).

(28) Doc. del 25 de diciembre de 1279, publ. por MESTRE PALACIO, A/calali, pág. 663 (A.C.A., Reg. Canc. $n .^{\circ} 42$, fol. 216).

(29) A.C.A., Reg. Canc. n. $0^{\circ} 75$, fol. 65.

(30) A 10 de abril de 1285, Pedro III el Grande ordena al baile del reino de Valencia que entregue a su arquitecto Guillermo de Barcelona unas cantidades de dinero para unàs obras en varios castillos, entre los cuales el de Pop (A.C.A., Reg. Canc. n. ${ }^{\circ}$ 22, fol. 46 v). En otro documento de 21 de abril de 1288 , el rey ordena al alimoxarif $B$. de Libiano que pague 
vitalicia del castillo, villa y término a la que aludimos más arriba (31). Aunque la concesión haya sido hecha por una duración limitada, es interesante observar que el documento real usa la expresión de alodio, que indica que no se trata ya de una mera alcaidia, sino de un verdadero señorío temporal, sin que el rey retenga otra cosa que las regalías, consistiendo principalmente en la alta justicia, el monedaje y el tercio diezmo. Esta concesión a Ramón de Villanova fue ampliada luego en 1306 y 1313, extendiéndose a su hijo Vitalón (32). En el documento de 1296, van enumerados los derechos señoriales que incluían los hornos, molinos y baños, los censos, el almagram y las çoffras y alfardas, siendo estos tres últimos tributos los más característicos de los que pagaban los mudéjares valencianos durante el siglo XIII (33).

En el año 1323, Jaime II dio a su hijo el infante Pedro varios lugares y castillos valencianos, entre los cuales se encontraba el castillo de Pop (34). Evidentemente, lo que pudo darse entonces en este castillo no era las rentas "señoriales" que seguían en poder de Ramón de Villanova o su hijo, según el tenor de las anteriores concesiones, sino el resto de los derechos reales sobre dicho castillo. El menoscabo que suponía para el infante el no poder cobrar las aludidas rentas fue tenido en cuenta, pues se le dio una compensación, valorándose estas rentas en 9.000 sueldos reales al año (35). La evolución de la alcaidía al señorío, que conviene situar dentro del marco de la creciente señorialización de los castillos valencianos a finales del XIII, fue concluida en 1328 al realizarse por el infante la venta del castillo y su valle a María Ladró, viuda de Ramón de Villanova y su hijo Vitalón, representado este último por su tío y tutor Vital de Villanova. La venta se hizo en feudo honrado, sine servicio y a costumbre de Cataluña, con las justicias, el mero y mixto imperio y toda jurisdicción, por un precio de 140.000 sueldos reales. En dicho precio, quedaron incluidos el tercio diezmo, el monetaticum y el mero y mixto imperio de la alquería de Murla, que el rey había concedido anterioremnte al infante con ocasión de la venta, y que este cedió en alodio a los Villanova (36). Queda bien claro en estos

a) alcaide. A. de Roars 1.500 sueldos en concepto de obras realizadas en el mismo (A.C.A., Reg. Canc. $n .^{\circ} 79$, fol. 22 v).

(31) A 26 de septiembre de 1296 (A.C.A., Reg. Canc. n. ${ }^{\circ}$ 194, fol. 265 r-v.)

(32) Documentos de 1305 y 1313 (A.C.A., Reg. Canc. n. ${ }^{\circ} 203$, fol. 92 y n. ${ }^{\circ} 210$, fol, 59),

(33) Sobre estos tributos, véase R. I. BURNS, Medieval Colonialism, Princeton, 1975, págs. 104-107, 162-173, y mi contribución a la historia de Valencia publicada bajo el título Nuestra Historia, vol. II, pág. 275 y III, págs. 70 y 77-80.

(34) A.C.A., Reg. Canc. n. ${ }^{\circ} 222$, fol. 11-25; véase también MESTRE PALACIO, Alcalali, págs. 664-667.

(35) A.C.A., Reg. Canc. $n .^{\circ} 222$, fol. 17-19.

(36) A.C.A., Reg. Canc..$^{\circ} 475$, fol. 90 y sig. 
hechos el deséo de éstos de adquirir el señorio más completo posible sobre todo el valle de Pop, incluida la alquería cristiana de Murla que no poseian plenamente, pero sobre la que iban a tener los derechos que tenía anteriormente el rey.

Habiendo pasado a ser el castillo de Pop y su valle un señorío privado, no encontramos en los años sucesivos sino un número muy contado de documentos sobre él en los archivos reales. Casi todos se refieren a la prestación de homenaje debido al rey por los Villanova (37). En 1382, sin embargo, vemos a Pedro IV conceder al miles Vital de Villanova una licencia para imponer, en Pop y Murla, una sisa o impuesto destinado a reparar las fortificaciones (menia) de estos lugares, que se encontraban en mal estado después de las guerras de mediados del siglo (38). El documento es interesante, pues parece indicar que, a finales del siglo XIV, todavía no estaba totalmente abandonado el castillo de Pop, sobre el que no sé si existe algún texto posterior a los primeros años del siglo $\mathrm{XV}$ a los que pertenece la última prestación de homenaje que consta en los fondos barceloneses (39).

Sobre la àlquería de Murla, que perteneció siempre a varios señores, hay muy poca documentación. Ya vimos que el lugar fue de Berenguer de Molins, y luego de Berenguer Mercer. Hay moradores cristianos a inicios del siglo XIV, pues en 1306 encontramos una venta de tierras en Benimeli hecha por un tal Arnaldo Calvet y su mujer Guillerma, de Murla (40). Según el Nomenclátor de Sanchis Sivera, la parroquia de Murla existiría desde por lo menos el año 1317, fecha en la que se edificaría una nueva iglesia (41). El P. Burns incluye también la parroquia de Murla entre las más antiguas de la diócesis, pero comprendida en la rectoría del Valle de Alaguar y del Valle de Pop (42). La iglesia fortificada que todavía existe en el poblado de Murla hace pensar, efectivamente, en un núcleo cristiano muy antiguo, aventurado en una zona de población musulmana (43). El hecho de que en 1328 el infante Pedro

(37) A.C.A., Libro de enajenaciones del Real Patrimonio en Valencia, s.v. "Pop», números 6 (1329), 9 (1336), 12 (1393) y 13 (1403).

(38) Doc. del primero de agosto de 1282 (A.C.A., Reg. Canc. n.॰ 1.279, fol. 2).

(39) Véase referencia en la nota 37.

(40) A.C.V., Perg. $n .^{\circ} 2.420$ del 14 de mayo de 1306.

(41) SANCHIS SIVERA, Nomenclátor geográfico-eclesiástico de los pueblos de la diócesis de Valencia, Valencia, 1922, pág. 307.

(42) R. I. BURNS, The Crusader Kingdom of Valencia, Harvard University Press, Cambridge, Mass., 1967, I, pág. 82.

(43) Véase F. G. SEIJO ALONSO, Castillos del pais valenciano, Alicante, 1978, pág. 135. 
vendió a los Villanova el terciodiezmo de Muria (44) indica que las tierras del lugar pertenecían entonces a cristianos, en contraste con lo que pasaba en el resto del valle de Pop donde los musulmanes pagaban al señor el almagram de tradición islámica (45). Este diezmo de Murla se menciona ya en un documento del Archivo de la Catedral de Valencia del año 1291 (46).

Un documento real del 23 de agosto de 1316 es una protección real concedida a Berenguer Mercer, ciudadano de Valencia, y a sus hombres cristianos y musulmanes, para la parte que posee en la alquería de Murla y su término (47). Pero después de la muerte de este Berenguer, su hermano Pedro, tutor del hijo de Berenguer, pidió permiso al rey para vender esta parte -o sea la mitad- de Murla, alegando la gran distancia entre Valencia donde residía su pupilo y este lugar (48). A mediados del siglo XIV, parece que Murla pertenecía a los Villanova, pues en un pergamino de la Catedral de Valencia de 1360, un Vidal de Vilanova se titula Señor de Murla (49). En cuanto a los derechos «eminentes" sobre Murla, que consistian en el terciodiezmo, el monedage y el mero y mixto imperio, hemos visto que pertenecían a los Villanova desde la venta que les había hecho el infante Pedro del castillo de Pop en el año $1328(50)$.

En cuanto al castillo de Murla, o del Puig d'Orba, sus restos se pueden ver todavía en un monte de 420 metros llamado "del Castellet", situado entre Murla y Orba. Se trata de una fortificación pequeña, con dos torres y una parte de vivienda, de tipo cristiano, cuya estructura corresponde perfectamente con la época de construcción revelada por el documento real de 1289 citado más arriba (51). Desde la misma fecha, este castillo fue tenido en feudo del rey, a costumbre de Barcelona, en primer lugar por los Mercer, que lo vendieron en 1331 a Isabel

(44) En los reinos cristianos ibéricos, el rey cobraba la tercera parte del diezmo eclesiástico o terciodiezmo (véase R. I. BURNS, The Crusader Kingdom of Valencia, I, págs, 149172). Según el documento de 1328 (véase referencia en la nota 36), el terciodiezmo de Murla fue vendido a los Villanova por el infante Pedro, conjuntamente con el feudo de Pop.

(45) Véase más arriba, y nota 33.

(46) A.C.V., Perg. 1831 de 27 de mayo de 1291.

(47) A.C.A., Reg. Canc. n. 213 , fol. 200 v, de 23 de agosto de 1316.

(48) A.C.A., Reg. Canc. n..$^{\circ} 482$, fol. 57 r., de 18 de diciembre de 1330.

(49) A.C.V., Perg. n. 3.306.

(50) Véase más arriba y referencia de la nota 36.

(51) Es equivocada la cronología de este castillo proporcionada por MESTRE PALACIO, A/ca/ali, pág. 139, en cuanto a sus orígenes. Sobre Orba, y algunos otros castillos cristianos del siglo XIII, véase mi breve estudio: "Châteaux chrétiens du royaume de Valence", en: Flaran I, Chateaux et peuplements en Europe occidentale du Xe au XVIIIe siècle, Auch, 1979, págs. 197-202. 
de Cabrera, mujer de Bernardo de Sarriá. A ésta, el rey concedió el mismo año que ejerciese en su lugar el mero imperio y toda jurisdicción civil y criminal en el castillo y su término (52), sin que sepamos como esta concesión concordaba con el mero imperio del lugar de Murla que, como vimos más arriba, pertenecía a los Villanova. La documentación conservada en los archivos reales alude a unos traspasos algo confusos del señorío del castillo de Murla a mediados del siglo XIV, hasta que, el año 1350, fue vendido por Artaldo de Foces, llamado también "de Cabrera", que, por lo tanto, podemos suponer era uno de los herederos de Isabel de Cabrera, a Vitalón de Vilanova y su madre María Ladró (53). En 1384 y 1393 es todavía un Ramón de Vilanova el que rinde homenaje al rey por el castillo de Murla (54). A finales del siglo XIV, pues, los Villanova habian logrado hacerse con el señorío de todo el antiguo valle de Pop.

Esta unidad así recuperada volvió a deshacerse más tarde. Sabemos que Murla, durante el siglo XV, perteneció a Joanot Martorell, autor de Tirant lo Blanc (55). A inicios del mismo siglo, encontramos una prestación de homenaje por Guillermo Martorell, abuelo de dicho Joanot, al que se nombra también Ramón de Villanova (56). Por otra parte, existió durante la época moderna un señorio, baronía y luego condado de Parcent, que incluia a Benichembla y Bernisa (57). Pero lo que nos interesaba era poner de relieve en primer lugar la evolución desde la alcaidía inmediata a la reconquista al señorío feudal que se forma a partir de finales del siglo XIII, y la concentración progresiva de los derechos señoriales, por concesiones reales y compras, en manos de una poderosa familia aristocrática valenciana, hechos que son unos buenos exponentes de la creciente tendencia a la señorialización, e incluso a la "feudalización", que afecta a las estructuras políticosociales valencianas durante la Edad Media (58).

(52) A.C.A., Reg. Canc. n. 482 , fol. 57 , y n. ${ }^{\circ} 483$, fol. $143 \mathrm{v}$.

(53) A.C.A., Libro de enajenaciones del Real Patrimonio en Valencia, fol. 186-188, n. ${ }^{\circ} 2$.

(54) Id., ibíd., números 30-33.

(55) Gran Enciclopedia de la región valenciana, vol. 7, pág. 39.

(56) MESTRE PALACIO, A/calali, pág. 139 y A.C.A.

(57) L. MAS Y GIL, Toponimia alicantina en la nobiliaria española, Alicante, pág. 125.

(58) Sobre este problema, véase el sugestivo estudio de A. FURIO y F. GARCIA, «Algunas consideraciones acerca del feudalismo valenciano", Estudios sobre Historia de España (Homenaje a Tuñón de Lara), Guadalajara, 1981, págs. 109-122. 


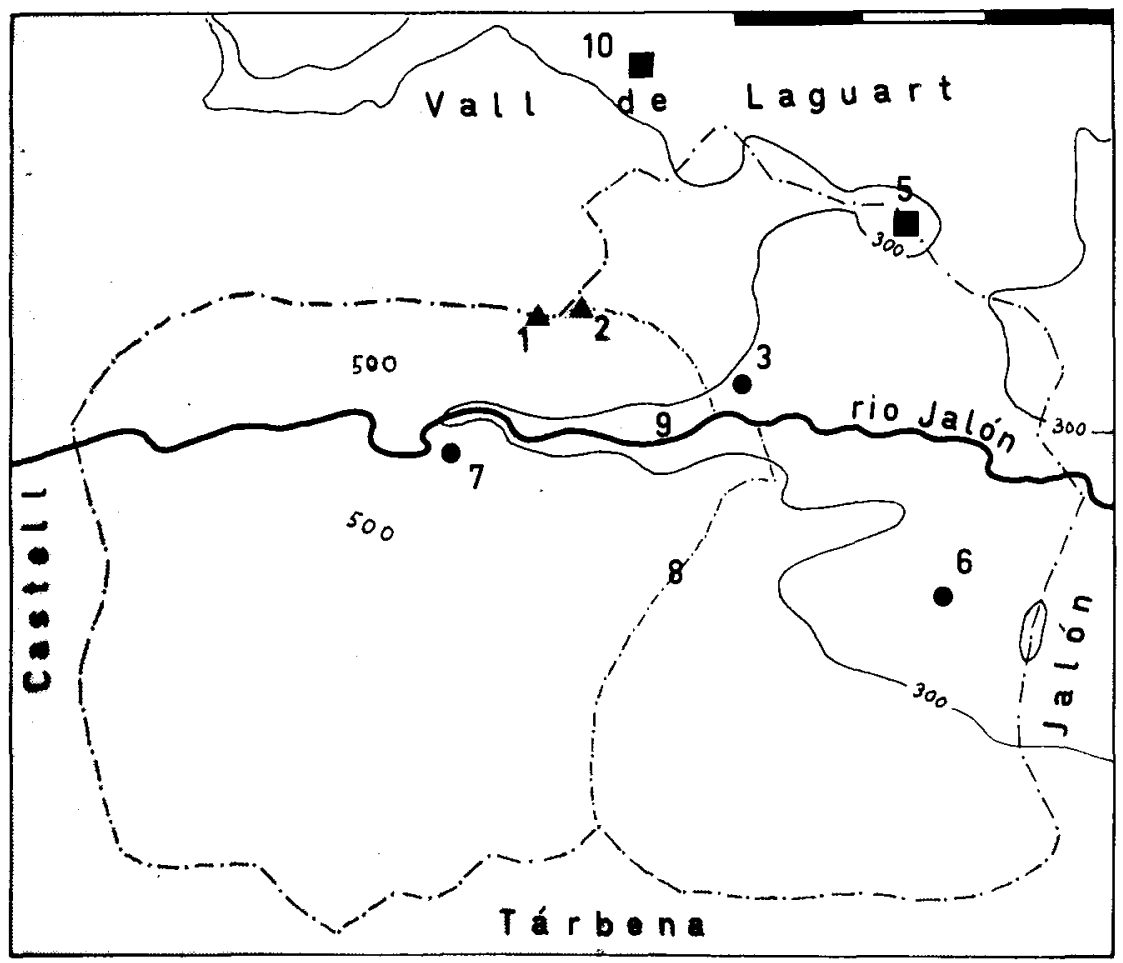

1. Mapa esquemático del valle de Pop: 1 y 2: Los dos picos del "Tossal de Cavall Verd", a 799 (1) y 761 (2) metros; 3: Murla; 5: castillo de Orba; 6: Parcent; 7: Benichembla; 8: Canesia; 9: Bernisa; 10: castillo de las Atzabaras (o de Laguart). Se indican los límites de los tres términos municipales que integran el valle y las curvas de nivel 300 y $500 \mathrm{~m}$. (alturas superiores a esa última en punteado). Escala: $3 \mathrm{~km}$. 


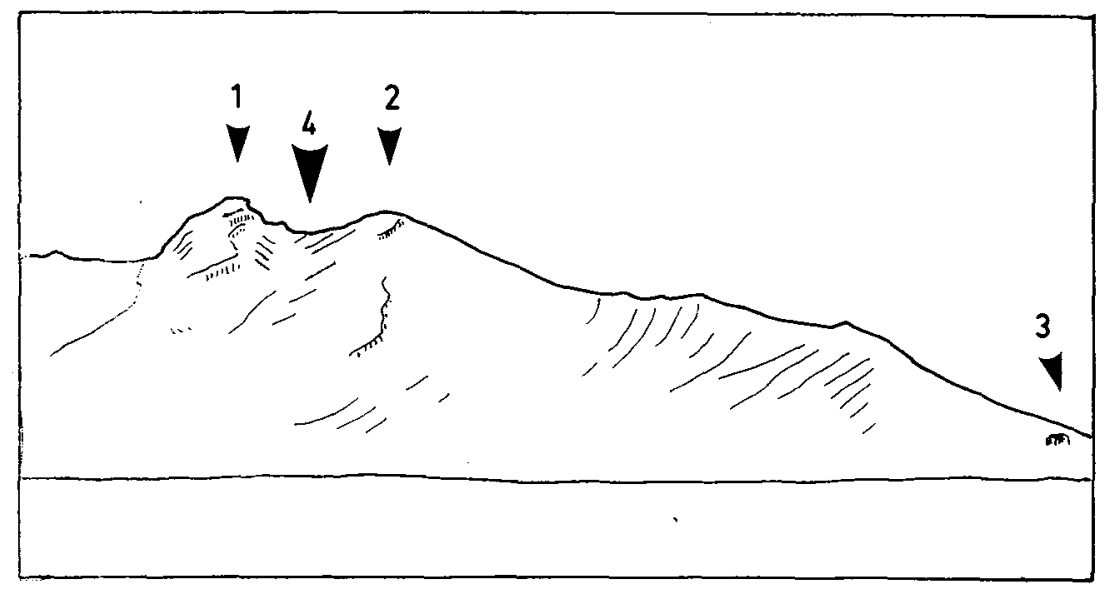

2. El "tossal del Cavall Verd", visto desde el valle de Pop: 1: pico mayor (799 m.); 2: pico menor (761 m.); 3: Murla; 4: zona con abundante cerámica. 